Artigo Original

\title{
Trajetórias singulares e plurais na produção de conhecimento de terapia ocupacional no Brasil
}

\author{
Singular and plural trajectories in the production of occupational therapy \\ knowledge in Brazil
}

\author{
Isadora Cardinalli ${ }^{a}$ (D), Carla Regina Silva ${ }^{a}$ \\ ${ }^{a}$ Universidade Federal de São Carlos - UFSCar, São Carlos, SP, Brasil.
}

Como citar: Cardinalli, I., \& Silva, C. R. (2021). Trajetórias singulares e plurais na produção de conhecimento de terapia ocupacional no Brasil. Cadernos Brasileiros de Terapia Ocupacional, 29, e2040. https://doi.org/10.1590/2526-8910.ctoAO2040

\begin{abstract}
$\underline{\text { Resumo }}$
Apresenta-se um resgate histórico da terapia ocupacional, composto por memórias individuais e coletivas do contexto brasileiro, indicando elementos constituintes de sua identidade e de seu campo de conhecimento. A pesquisa histórica e epistemológica analisou, com base no método cartográfico, as relações entre características singulares e plurais de cinco terapeutas ocupacionais e suas trajetórias profissionais dedicadas para a construção de conhecimento na área. Com base nas narrativas dessas interlocutoras, foi perceptível a construção coletiva de histórias da profissão em seus contextos, destacando aspectos comuns de suas experiências e a pluralidade da produção no campo. Destacaram-se 14 categorias que se relacionam com: o desconhecido e a graduação incipiente; a necessidade da formação continuada; a repressão e resistência do/ao Regime Militar; a organizaçáo política da categoria; investimento na pesquisa em terapia ocupacional; compreensôes sobre especificidades; adoção/enunciação de perspectivas, métodos ou campos; redes de suporte; crítica a padróes acadêmicocientíficos; encantamento pela profissão; prazer em produzir; protagonismo feminino e o conhecimento atrelado à prática. A pluralidade desse campo de saberes é evidenciada pelas profissionais, assim como pela tessitura de uma rede de conhecimentos. São identificados os desafios, redes de suporte, críticas, encantamentos, protagonismo, produçôes e perspectivas diversas pela valorização à solidariedade entre as singularidades que constroem a pluralidade dessa identidade profissional. Nessa compreensão, o conhecimento é uma construção teóricometodológica processual efetivado em redes de relaçôes afetivas e éticas, ainda que conviva com a hierarquização hegemônica dos campos, temas e grupos.
\end{abstract}

Palavras-chave: Terapia Ocupacional/Tendências, Conhecimentos/Epistemologia, História, Cultura. 


\begin{abstract}
$\underline{\text { Abstract }}$
This paper presents a historical rescue of occupational therapy, composed of individual and collective memories of the Brazilian context, indicating elements that constitute its identity and its field of knowledge The historical and epistemological research analyzed, from the cartographic method, the relations between singular and plural characteristics of five occupational therapists and their professional trajectories dedicated to the construction of knowledge in the area. From the narratives of these interlocutors, it was noticeable the collective construction of stories of the profession in their contexts, highlighting common aspects of their experiences and the plurality of production in the field. We highlight 14 categories that relate to: the unknown and the incipient graduation; the need for continuing education; the repression and resistance of the Military Regime; the political organization of the category; investment in occupational therapy research; understanding of specificities; adoption/enunciation of perspectives, methods or fields; support networks; criticism of academic-scientific standards; enchantment by profession; satisfaction in producing; female protagonism and knowledge linked to practice. The plurality of this field of knowledge is evidenced by professionals, as well as by the weaving of a knowledge network. We identified the challenges, support networks, criticisms, enchantments, protagonism, productions, and diverse perspectives by valuing the solidarity between the singularities that build the plurality of this professional identity. In this understanding, the knowledge is a procedural theoretical-methodological construct effected in networks of affective and ethical relationships, although it coexists with the hegemonic hierarchy of fields, themes, and groups.
\end{abstract}

Keywords: Occupational Therapy/Trends, Knowledge/Epistemology, History, Culture.

\title{
Apresentaçáo
}

A recuperação histórica da produção de conhecimento da terapia ocupacional no Brasil apresenta proposiçôes reconhecidas pelo campo por incorporar mudanças de concepçóes efervescentes da década de 1980 (Nascimento, 1990; Pinto, 1990; Machado, 1991; Soares, 1991; Francisco, 2001; Medeiros, 2010). Tais proposições acompanhavam transformações políticas e epistemológicas do país e conduziram novos rumos e perspectivas para uma profissão consciente de sua realidade. A partir de então, surgiram composições e perspectivas teórico-metodológicas arquitetadas na relação com outras áreas do saber, produzindo conhecimentos implicados, contextualizados e articulados com o percurso da terapia ocupacional no país.

Este artigo tem como objetivo apresentar uma composição entre trajetórias e produções de conhecimento, destacando expressóes singulares e alinhavando aspectos comuns que perpassam construçóes plurais na terapia ocupacional, vista como um campo de saberes teórico-práticos indissociáveis.

Comumente, esse cenário é tomado pelo ponto de vista de trajetórias acadêmicas, porém, essa hierarquização das estruturas de poder relacionadas ao conhecimento ignora construções intimamente relacionadas ao perfil profissional sem tradição acadêmica. Para incorporar outras vozes nesta construção coletiva, buscou-se revisitar histórias junto com 
interlocutoras da atualidade, contemplando personalidades do circuito acadêmicocientífico institucional e de outros contextos independentes de estudo e investigação em terapia ocupacional, compondo com outras perspectivas teórico-metodológicas que se inscrevem e escrevem essas histórias.

Para tanto, efetivou-se uma pesquisa que buscou modulaçóes na construção de trajetórias e conhecimentos em terapia ocupacional no Brasil, baseando-se em memórias e narrativas, compreendendo-as enquanto trajetórias singulares e plurais para as histórias possíveis de serem contadas sobre a profissão no país. Para Nora (2016), a memória é um elo eterno, vivo e afetivo entre passado e presente, aberta à dialética da lembrança e do esquecimento, ao mesmo tempo individual e coletiva. Todo registro de memória se torna história, que por sua vez é uma reconstrução problemática e incompleta, uma operação intelectual que se encontra no passado, pertencente a todos e a ninguém ao mesmo tempo (Nora, 2016).

Como a memória é construída social e individualmente, torna-se um elemento constituinte do sentimento de identidade. Isso não significa deixar de considerar a crítica, o que envolve ponderar sobre as especificidades de contextos e relaçóes hierárquicas e heterogênicas, por isso, é interessante admitir a pluralidade das histórias, realidades e cronologias (Pollak, 1992).

$\mathrm{Na}$ contramão da tentativa ilusória e perigosa de contar "uma história única” (Adichie, 2009), compreendemos a representação singular de protagonistas terapeutas ocupacionais sempre dada na pluralidade deste coletivo. Optou-se por afirmar as potencialidades e os limites temporais, espaciais e afetivos das memórias, conduzindo uma reflexão interpretativa e analítica, em vez de uma reconstrução linear da história.

A pesquisa da qual este artigo deriva analisou relaçôes entre características das trajetórias e proposiçóes de terapeutas ocupacionais que se dedicaram à produção de conhecimento sobre a terapia ocupacional no Brasil, buscando revelar singularidades e pluralidades, atravessadas por processos comuns frente à diversidade de saberes e fazeres dessa profissáo (Cardinalli, 2017).

Para tanto, seguiu-se dois procedimentos para convidar seis profissionais que investigassem a terapia ocupacional e produzissem conhecimentos específicos sobre ela no Brasil. Três delas foram identificadas em um levantamento realizado em 2015, no currículo Lattes do Conselho Nacional de Desenvolvimento Científico e Tecnológico - CNPq, que analisou as trajetórias de 196 profissionais, membros em 31 grupos de pesquisa de terapia ocupacional, buscando quem havia investido em compreender temas estruturais e transversais na/da terapia ocupacional, como: histórias, panoramas do ensino, pesquisa ou produção, epistemologias, fundamentos, conceitos, referenciais, perspectivas, identidades, entre outros.

As outras três profissionais identificadas por suas atuações na assistência ou na clínica foram indicadas pelas primeiras interlocutoras, sendo todas reconhecidas por seus investimentos e proposiçôes conceituais em terapia ocupacional. Cinco das convidadas puderam se tornar interlocutoras e autorizaram a divulgaçáo de suas identidades e narrativas por meio dos respectivos Termos de Consentimento Livre e Esclarecido ${ }^{1}$ (Cardinalli, 2017).

${ }^{1}$ Todos os preceitos éticos foram respeitados. 
As interlocutoras foram entrevistadas, seguindo um roteiro semiestruturado com algumas questôes específicas sobre suas trajetórias e produçóes e também puderam relatar, de forma livre, em uma conversa não estruturada, suas trajetórias profissionais, revelando fatos que contribuíram para despertar e/ou alimentar seu interesse em pensar a terapia ocupacional. As entrevistas foram transcritas e passaram por apreciação das interlocutoras, com possibilidade de revisão ou nova redação, para aprovação do texto final.

A concepção de produção e composição dos dados, em vez de coleta e tratamento, segue Pistas do Método da Cartografia, preconizando o fazer-pensar conjunto e processual como parte da construção do conhecimento sem necessariamente se prender a hipóteses prédefinidas, mas considerando os procedimentos como um campo de problemas e fluxos de sentido que conduzem o caminhar da pesquisa. Assim, os dados são produzidos pelos efeitos das intensidades do processo, construindo uma rede de sentidos entre os elementos, que se exerce sobre a pesquisadora, as interlocutoras e os dados (Passos et al., 2012).

Foi realizada uma escuta minuciosa e acolhimento dos conteúdos emergidos das entrevistas. A composição dos dados foi uma construção colaborativa em interlocução, tendo as experiências, pensamentos e reflexóes singulares orientando a interpretação de fenômenos culturais, sociais e históricos. Durante a análise, deu-se atenção legítima às diferentes vozes, abrangendo interpretaçóes e discursos contra-hegemônicos, sem generalizaçóes e preconceitos (Schmidt \& Toniette, 2008).

As sutilezas desses processos conduziram os procedimentos analíticos, os quais puderam ser acompanhados pelos registros afetivos e questionadores em diário de campo. Nesse sentido, a análise incorpora os processos da pesquisadora, considerando sua implicaçáo, assim como da trajetória viva da pesquisa e dos resultados derivados. Esses cuidados são compreendidos como pontos de força que conduzem e consideram a produção coletiva do conhecimento (Passos et al., 2012).

A flexibilidade garantiu o caráter processual dos procedimentos metodológicos, indicando caminhos de análise, mas esses permaneceram abertos a imprevistos das relaçóes concretas estabelecidas no campo. Adotou-se procedimentos que permitissem que a pesquisa permanecesse em movimento, sendo capaz de acompanhar o que se apresentou como interessante de forma menos controlada, incluindo sugestóes das interlocutoras (Schmidt \& Toniette, 2008).

Com trechos destacados das transcriçōes, por apresentarem pontos de força individuais ou coletivos, foi-se experimentando configurações, como em uma edição de vídeo experimental em que não se deseja um controle total do resultado final ou promover cortes secos, visando manter tudo que parecesse interessante, assim como a ideia de inacabamento. Com isso, desenharam-se grupos de sentidos: percursos históricos, expressóes singulares, composição em uma rede plural de conhecimentos em terapia ocupacional e estratégias compartilhadas ou comuns.

Ainda que se esperasse olhar para singularidades e expressões plurais, na construção da pesquisa se apresentaram tessituras do comum, uma conversa inevitável entre as interlocutoras, incluindo relaçóes de intimidade. A seguir, composiçóes serão apresentadas, em uma reafirmação dos grupos de sentidos, destacando fatos contextuais marcantes apresentados pelas narrativas. 


\section{A produçáo de conhecimento no Brasil}

É o momento de desempenhar a alta função da lembrança. Não porque as sensaçôes se enfraquecem, mas porque o interesse se desloca, as reflexóes seguem outra linha e se dobram sobre a quintessência do vivido. Cresce a nitidez e o número de imagens de outrora, e esta faculdade de relembrar exige um espírito desperto, a capacidade de não confundir a vida atual com a que passou, de reconhecer as lembranças e opô-las às imagens de agora (Bosi, 1994, p. 81).

A produção e diferenciação do conhecimento científico da terapia ocupacional no Brasil foi impulsionada na década de 1980, com o processo de institucionalização da profissão no país, os primeiros ingressos de terapeutas ocupacionais na pós-graduação stricto sensu e o desenvolvimento de pesquisas. A necessidade de capacitação docente e de estruturação do ensino em terapia ocupacional foi um grande mobilizador das primeiras pesquisas e primeiros diálogos da categoria para compreender e sistematizar temas fundamentais e outras interfaces para a formação graduada (Lopes, 1991; Emmel \& Lancman, 1998; Lancman \& Emmel, 2003; Salles \& Matsukura, 2016).

As políticas de expansão do ensino superior da década de 1970 e o fortalecimento dos movimentos pela redemocratização do país que demandavam a constituição dos direitos sociais, após a Ditadura Militar, contextualizaram uma nova perspectiva política que ampliou e ofereceu maiores condiçóes para a construçáo de respostas às demandas significativas da terapia ocupacional. Neste sentido, o encontro da produção teórico-prática com as ciências humanas e sociais foi essencial para a construção de um novo cenário, problematizando o papel eminentemente técnico e conquistando também a necessidade do exercício ético e político da profissão. Referenciais da filosofia, história, psicologia social, sociologia, antropologia, educação, saúde coletiva, economia e artes passam a ser incorporados. No fim da década de 1990, também surgem os primeiros programas de pósgraduação interdisciplinares do país, que ampliaram as possibilidades de conexáo entre áreas do conhecimento (Mângia, 1999; Barros et al., 2002; Oliver, 2008).

$\mathrm{Na}$ década seguinte, foi possível verificar que terapeutas ocupacionais se inseriam em quase todos os grandes campos do saber - Biológicas, Engenharias, Tecnologia, Ciências da Saúde, Humanas, Sociais e Artes, dado o aumento de ofertas e áreas nos programas de pós-graduação das universidades, principalmente públicas (Cardinalli, 2017).

Os terapeutas ocupacionais passaram a atuar mais fortemente em equipes multidisciplinares e interdisciplinares, fazendo com que tais temas aparecessem em suas produções, assim como a transdisciplinaridade (Galheigo, 1999). A profissão no Brasil inaugurou distintos campos de práticas, evidenciando sua construção diversa e plural em composição com outras áreas do conhecimento. Esse processo de investimento acadêmico, científico e profissional cresceu na direção de afirmar determinadas especialidades profissionais, dentre elas, reabilitação física, saúde mental, saúde coletiva, hospitalar, gerontologia, campo social, educação, trabalho e cultura. Por outro lado, parece que se esvaziou a produçáo em torno dos conhecimentos transversais que pudessem tecer perspectivas identitárias na profissão (Cardinalli, 2017).

Isso se manteve até que algumas publicaçóes levantaram o debate em torno dessa diversidade como característica da identidade profissional: indicando uma busca por coesão em teorias e práticas desenvolvidas com as áreas afins (Lancman, 1998), legitimando a 
existência das múltiplas terapias ocupacionais (Mângia, 1998), questionando a fragmentação racional do paradigma científico moderno (Lima, 1997; Quarentei, 1999) ou propondo pensar a identidade profissional de forma flexível, positiva (Furtado, 1999), feita de diferenças, processual, complexa (Lima, 1999), plural, com multidimensóes e multirreferenciais, transdisciplinar e fluida em oposição a uma identidade única, rígida e universal (Galheigo, 1999; 2007).

A questão da identidade profissional não se faz esclarecida e retorna timidamente de forma cíclica ao debate profissional, apresentando novas proposiçóes, assim como se espera do processo contínuo de produção de um campo científico. Nas últimas décadas, fortalece a preocupação em torno da institucionalização da pesquisa e da pós-graduação em terapia ocupacional, em uma relação dúbia e contraditória com a produtividade científica e um diálogo, ora crítico, ora condizente, porém, cada vez mais próximo a tendências internacionais (Cardinalli, 2017).

A construção de conhecimento em terapia ocupacional no Brasil teve fortes influências internacionais, sobretudo da terapia ocupacional hegemônica dos países europeus, Estados Unidos da América e Canadá, mas também na interlocução com países vizinhos, como a Argentina. Porém, evidencia-se a interação com outros campos do saber, pois, na busca por responder demandas teórico-práticas dos contextos e realidades brasileiras, contribuíram de formas singulares na produção de saberes próprios, localizados e comprometidos com os cotidianos profissionais e seus saberes e fazeres culturais intrínsecos.

Tendo em vista a relação entre singularidades e processos comuns, serão recuperadas trajetórias profissionais em uma tessitura de percursos individuais e coletivos, que revelam debates, inquietaçóes e concepçóes díspares e peculiares que compóem uma rede plural de conhecimentos da terapia ocupacional no Brasil.

\section{Trajetórias singulares em processos compartilhados}

As interlocutoras deste trabalho e protagonistas das trajetórias que serão apresentadas foram Maria José Benetton, Sandra Maria Galheigo, Roseli Esquerdo Lopes, Maria de Lourdes Feriotti e Mariangela Scaglione Quarentei, trazendo relatos de histórias da terapia ocupacional, majoritariamente, vividas no estado de São Paulo.

Maria José Benetton, reconhecida como Jô Benetton, ingressou no curso de Terapia Ocupacional na Universidade de Sáo Paulo (USP), em 1968, tendo se formado em 1970. Pioneira de inúmeras conquistas na profissão, foi aprovada e assumiu o primeiro concurso de terapia ocupacional do estado de São Paulo, em 1971, assim como, em 1973, o concurso do Hospital da Faculdade de Ciências Médicas da Santa Casa de Misericórdia, vaga destinada para criar e coordenar o primeiro Hospital Dia da cidade de São Paulo.

Jô foi estudar nos Estados Unidos da América e na França para trazer novos referenciais para os profissionais brasileiros. Durante a Ditadura Militar, foi expulsa da Santa Casa pelo Departamento de Ordem Política e Social (DOPS), ficando seis anos desempregada. Nesse período, participou da criação do Hospital Dia A Casa, em 1979, onde atuou até 1983, quando foi para Cuba passar um mês a convite do grupo ligado ao Frei Betto e ao Partido Comunista. Em 1980, também iniciou o Centro de Estudos em Terapia Ocupacional (CETO). Assumiu uma vaga na Universidade Federal de São Paulo (UNIFESP), tendo exercido a profissão entre 1983 e 1996. Entre 1985 e 1989, realizou seu mestrado em Psicologia Social na Pontifícia Universidade Católica (PUC), com uma investigação sobre a 
terapia ocupacional. Seu doutorado foi em Saúde Mental, entre 1990 e 1994, na Universidade Estadual de Campinas (UNICAMP), voltado para a criação de seu método profissional. Em 1995, lançou a Revista do CETO. Entre 1996 e 2002, lecionou na Universidade de São Paulo (USP). Em 2005, o CETO foi atualizado para Centro de Especialidades em Terapia Ocupacional e, em 2015, o Método da Terapia Ocupacional Dinâmica (MTOD) foi o primeiro método brasileiro de terapia ocupacional a ser registrado.

Sandra Maria Galheigo entrou para o curso de fisioterapia em 1975, na Escola de Reabilitação da Associação Brasileira Beneficente de Reabilitação (ABBR) do Rio de Janeiro, mas no segundo ano (momento de divisáo das turmas) optou pela terapia ocupacional pela proximidade com a saúde mental e as ciências sociais, formando-se em 1977. Sua carreira docente se iniciou em 1978, na FRASCE - Faculdade de Reabilitaçáo da Associação de Solidariedade da Criança Excepcional, onde ficou até 1979. Nesse período, contribuiu para a Associação de Terapeutas Ocupacionais do Rio de Janeiro e a Associaçáo Brasileira de Terapia Ocupacional, registro de uma militância política que se tornou marca importante em sua trajetória.

Em 1980, entrou para o corpo docente da PUC de Campinas - São Paulo. Iniciou mestrado em Educação na UNICAMP, entre 1981 e 1988. Participou do grupo interinstitucional formado por docentes de terapia ocupacional para discussão sobre fundamentos da profissão. Em 1989, iniciou doutorado em Ciências Sociais, na Universidade de Sussex, na Inglaterra, concluído em 1996. Participou da formação do Grupo Interinstitucional sobre Terapia Ocupacional Social, o Metuia, em 1998, do qual fez parte até 2005. Dentre os cargos de representação, em 1998, compôs a segunda Comissão de Especialistas em Ensino de Terapia Ocupacional junto ao Ministério da Educação (MEC); em 2000, participou da criação da RENETO - Rede Nacional de Ensino em Terapia Ocupacional, sendo a primeira presidente; em 2004, compôs a Comissão Assessora da Área de Terapia Ocupacional do MEC e também se tornou membro do Banco de Avaliadores (BASis). Em 2005, tornou-se docente da USP. Atualmente, representa a profissão em organizaçóes internacionais e investe nos fundamentos da profissão, com enfoque em referenciais teórico-metodológicos da Terapia Ocupacional Crítica.

Maria de Lourdes Feriotti estudou na USP entre 1976 e 1978, revelando características militantes de sua turma de graduação que, em período militar, resistiu como pôde à repressão de forma ativa e coletiva. Após formada, buscou o primeiro grupo de estudos em terapia ocupacional, coordenado por Jô Benetton, tendo significado influência marcante no campo da saúde mental. Sua carreira docente iniciou em 1982, na PUC de Campinas, onde viveu processos de trabalho inovadores do ponto de vista da profissão e da organização universitária. Entre 1984 e 1985, também lecionou na USP. Participou do grupo interinstitucional de estudos sobre fundamentos da profissão, como Sandra, por lecionar disciplinas de tais conteúdos e se dedicar ao tema em suas investigaçóes e proposiçóes.

Em 2000, criou, junto com colegas, o G.E.I.T.O. (Grupo de Estudos Interdisciplinares em Terapia Ocupacional), oferecendo estudos e supervisóes em terapia ocupacional, com enfoque interdisciplinar. Seu mestrado em Educação, realizado entre 2005 e 2007, representa um dos momentos marcantes de uma relação conflitante e apaixonante com a academia. Em 2010, participou da formação do curso de Terapia Ocupacional da Universidade Federal da Paraíba (UFPB), mas retornou à PUC-Campinas, em 2014. Atua na gestão junto à Coordenação de Saúde Mental da Secretaria Municipal de Saúde de 
Campinas, é supervisora clínico-institucional e promove, junto com o G.E.I.T.O., a Teoria da Complexidade para a Terapia Ocupacional.

Mariangela Scaglione Quarentei ingressou na Universidade de São Paulo, em 1976, na mesma turma de Lourdes, porém, formou-se em 1979. Desenvolveu atividades políticas junto a Centros Acadêmicos, à reconstrução da União Nacional dos Estudantes (UNE), ao movimento pela creche pública na cidade de São Paulo e à reforma do tratamento psiquiátrico no Brasil, participando da organização do primeiro Encontro de Trabalhadores de Saúde Mental, em 1979. Durante a graduação, entrevistou Jô Benetton e se encantou com sua defesa pela terapia ocupacional, começou a participar de seu grupo de estudos, no qual, após formada, chegou a ser monitora e depois a ministrar disciplina no CETO. Entrou no concurso do Manicômio Judiciário de São Paulo, em 1980, porém, não assumiu, pois foi chamada para trabalhar na Faculdade de Medicina da Universidade Estadual Paulista de Botucatu (FMB/UNESP), onde havia feito estágio voluntário, durante a graduação, por indicação de Jô.

Iniciou o trabalho em Botucatu em 1980, como terapeuta ocupacional e supervisora de estágio no Hospital Dia e no ambulatório, lecionou para alunos da graduação de medicina e residentes da psiquiatria. Em 1981, começou a receber estagiários de terapia ocupacional da Universidade Federal de São Carlos (UFSCar). Em 1985, criou, em Botucatu, o primeiro Programa de Aprimoramento Profissional de Terapia Ocupacional e Psiquiatria do estado de São Paulo. Entre 2003 e 2012, criou grupos de estudo e supervisão em Botucatu e em São Paulo, os quais integraram o Coletivo de Estudos de Terapia Ocupacional e Produção de Vida. Nos últimos anos, atuou junto ao Laboratório do Processo Formativo em São Paulo e continua investindo na perspectiva do Coletivo junto ao Laboratório de Atividades Humanas e Terapia Ocupacional, na UFSCar.

Roseli Esquerdo Lopes estudou na Universidade de São Paulo entre 1977 e 1979. Nesse período, conheceu Jô Benetton (sua defesa pela terapia ocupacional também a motivou a investir na profissão) e participou do movimento estudantil. Formada, participou do movimento para abertura de concurso público para terapia ocupacional, pela Secretaria de Estado da Saúde do estado de São Paulo. Assim que foi publicado o concurso, em 1980, Roseli prestou e passou (assim como Mariangela), assumindo uma vaga no Manicômio Judiciário. Em 1984, foi contratada como docente pela USP. Fez mestrado em Educação na UFSCar entre 1985 e 1991. Nesse período, teve uma experiência em Cuba. Participou da organização dos encontros nacionais de docentes da profissão, desde o primeiro, em 1986.

Em 1991, entrou no concurso como professora efetiva na UFSCar. Entre 1995 e 1999, fez doutorado em Educação pela UNICAMP. Participou da formação do Grupo Metuia, junto com Sandra, onde permanece desde então. Tem sua inserção no Programa de PósGraduação em Educação (PPGE) da UFSCar desde 2003 e também no Programa de PósGraduação em Terapia Ocupacional (PPGTO), desde sua formação, em 2009. Conquistou a primeira vaga de professora titular, em 2012, do Departamento de Terapia Ocupacional da UFSCar. Participou da reformulação dos Cadernos Brasileiros de Terapia Ocupacional, atua junto à Rede Nacional de Ensino e Pesquisa em Terapia Ocupacional (RENETO), tendo ocupado também diversos cargos representativos em sua trajetória, assim como Sandra e, em diversas oportunidades, junto com ela. Afirma seu atual investimento na pesquisa sobre os fundamentos e história da terapia ocupacional. 
No trabalho de pesquisa, durante a escuta individualizada dessas trajetórias, foi possível encontrar inúmeros pontos de convergência e compartilhamentos de processos em suas trajetórias. Ao analisá-los, foram reconhecidos elementos que convergiram entre as narrativas e corroboraram a construção de conhecimento em terapia ocupacional, sendo eles: o interesse pelo desconhecido; uma graduação incipiente e precária; formação continuada em terapia ocupacional; marcas da repressão e resistência do/ao Regime Militar; e desenvolvimento e organização política da categoria.

$\mathrm{O}$ interesse pelo desconhecido mostra um encadeamento de situaçôes que se iniciou com a curiosidade pela profissão recém-descoberta e derivou em um processo de questionamento que compôs o movimento de transformação da profissão no país. A graduação em terapia ocupacional, para algumas, foi descoberta por acaso e reúne curiosidades sobre a escolha do curso, como o foco no cuidado, a ideia da junção de disciplinas (médicas, biológicas, humanas, psicológicas, artísticas etc.), a união de diferentes áreas e interesses ou, até mesmo, a intermediação de desejos pessoais (nas artes) com pressóes familiares (no sentido da medicina) no momento de escolher a formaçáo, por exemplo. O interesse de uma descoberta inicial conduziu processos de autonomia, liberdade e novas aprendizagens no cotidiano universitário.

Períodos de formação graduada bastante próximos, por vezes simultâneos, sendo a maioria em Sáo Paulo, no fim da década de 1970, revelam marcas compartilhadas de uma graduação incipiente e precária. A escassez de bibliografias que, até então, eram apenas alguns manuais e jornais estrangeiros, parte deles traduzidos e circulados na informalidade, derivava no ensino oral da prática, transmitida por pouquíssimos terapeutas ocupacionais que já eram formados, sendo a maioria convidados que contavam sobre suas atuaçóes, sem sistematização do conhecimento e com características biomédicas, tecnicistas e conservadoras. A falta de efetivação de suas expectativas as convocou para a construção, alimentando um profundo engajamento pela profissão, o que ressignificaria suas compreensôes dali em diante.

A formatura viria acompanhada da emergente necessidade de qualificação, levando-as à participação, ou mesmo proposição de grupos de estudo como uma alternativa para formação continuada em terapia ocupacional. A possibilidade de diálogo com outros profissionais caminhou naturalmente para a construção de grupos autônomos, cumprindo um papel que a universidade ainda não alcançava. $\mathrm{O}$ investimento de Jô Benetton em estudar a profissão gerou o primeiro grupo independente na cidade de São Paulo, pelo qual passaram em algum momento Lourdes, Mariangela e Roseli, com formação que permanece autônoma e reconhecida. Consequentemente, também houve procura pela pós-graduação lato e/ou stricto sensu em áreas afins, como era possível naquele momento, buscando por conexóes com a terapia ocupacional, sobretudo em programas da Educação, mas também Filosofia, Psicologia e Ciências Sociais.

Para além do conteúdo formativo, vê-se uma geração, ou gerações muito próximas, que compartilham marcas da repressão e resistência dolao Regime Militar, com a militância pródemocracia e por direitos. Isso fortaleceu o envolvimento com coletivos e/ou movimentos sociais e o posicionamento social e político. As mesmas questôes conduziam à proposiçáo de alternativas para responder às demandas desse contexto social em que atuavam, para organizar a categoria profissional e para participar das lutas em prol dos direitos das populaçôes envolvidas. Consequentemente, também sofreram com represálias, violaçôes, sançóes e perseguiçóes, tanto na universidade como em diferentes postos de trabalho. 
Essas profissionais estiveram no início do desenvolvimento e organização política da categoria, na criação ou participação de associaçóes, encontros e congressos, direcionados à reformulação curricular dos cursos, considerando as reivindicaçóes corporativas, dialogando e coproduzindo conhecimentos na área, entre outros temas. Foram ressaltados os congressos e outros encontros profissionais como importantes espaços de produção e troca para a categoria. O primeiro Encontro Nacional de Docentes de Terapia Ocupacional (ENDTO), por exemplo, foi uma das proposiçóes no sentido da promoção da discussão, em nível nacional, sobre a formação profissional e a produção de conhecimento na área.

Nesse sentido, ressalta-se a afirmação do papel político na terapia ocupacional. Sandra, Roseli e Lourdes reúnem inúmeras representaçôes que exerceram em associaçóes nacionais e internacionais da categoria profissional ou relacionadas à formaçáo superior, em comissóes de especialistas, rede nacional de ensino e pesquisa, entre outros, como a avaliação da educação superior no país. Na esfera da atuação profissional, Jô, Mariangela e Roseli relataram a participação em movimentos que derivaram, por exemplo, na abertura das primeiras vagas para terapeutas ocupacionais em concursos públicos no estado de São Paulo, ou mesmo na Luta Antimanicomial e na Reforma Psiquiátrica. Lembrando também do alcance da política de expansão das universidades federais, que ofereceu possibilidades para as carreiras acadêmicas de Roseli e Lourdes.

\section{Reconhecendo pluralidades na produçáo de terapias ocupacionais}

Entre caminhos e processos compartilhados, há desenvolvimentos singulares que convocam a produção de sentidos na terapia ocupacional. A investigação em terapia ocupacional, por exemplo, esteve associada a reflexóes e formulaçóes conceituais que caracterizaram a construção do campo de conhecimento para a profissão. Quem realizou pós-graduação stricto sensu, enfrentou mais dificuldade para estudar terapia ocupacional, dependendo do quanto o programa e a orientação possibilitaram abertura para isso. Dentre os investimentos à pesquisa em terapia ocupacional, estiveram em torno de temas como a formação em terapia ocupacional, estrutura curricular dos cursos, influência biomédica e positivista na formação e nas práticas, métodos, fundamentos e histórias da profissão.

A aproximação com as ciências humanas e sociais e a adoção de seus referenciais aconteceu com todas as interlocutoras, estimulando discussóes filosóficas, epistemológicas, sobre fundamentos, histórias e identidades da profissão. A singularidade-plural do caminhar de cada interlocutora, a cada nova possibilidade de rota, interesse, curiosidade ou condução de suas formaçóes requereu a afirmação de referenciais teórico-metodológicos em suas produçóes. A experiência docente, em particular com disciplinas de conhecimentos específicos em terapia ocupacional, foi responsável pela revisão da estrutura curricular nos cursos e pela produção de compreensóes sobre especificidades da profissão.

Os "fundamentos" contêm a ideia de construção de um campo, da explicação daquilo que dá sustentação para esse campo, no nosso caso, para essa prática. [...] Tenho certeza que para eu falar de fundamentos tomo alguns referenciais, mas isso náo os torna referenciais da terapia ocupacional. [...] Essa diversidade da terapia ocupacional também é uma diversidade de caminhos (Roseli Lopes).

Independente de sua perspectiva teórico metodológica [...] que são reflexôes mais avançadas, sobre a constituiçáo dos saberes da terapia ocupacional [...] acho que tem 
conceitos-chave como a atividade, o cotidiano, modos de vida, e um conjunto de outros conceitos como participação social, participação cidadã, inclusão social, transformação social, cidadania, autonomia que são importantes (Sandra Galheigo).

A adoção e a identificação de referenciais teórico-metodológicos, aliadas às demandas da intervenção e da investigação, possibilitaram a construção ou efetivação de perspectivas, métodos, concepções e campos de atuação para a terapia ocupacional. Nos relatos, há predomínio também da compreensão de que existem outras possibilidades de se conceber e de interpretar a realidade profissional. $\mathrm{Na}$ composiçáo entre as singularidades-plurais, nas trajetórias de cada interlocutora houve a adoção elou enunciação de concepçôes, perspectivas, métodos ou campos: Método da Terapia Ocupacional Dinâmica, Método da Complexidade, Perspectiva Crítica na Terapia Ocupacional, Terapia Ocupacional como Produção de Vida e Terapia Ocupacional Social, como relatam, respectivamente, a seguir:

Eu acho que tem ideologias diferentes na terapia ocupacional, são ideologias porque são o início da ideia, o núcleo central da ideia é diferente de uma para outra. São lógicas diferentes, e se tratando de lógica é Ideologia e Epistemologia. E as três ideologias partem dos três paradigmas diferentes: um da doença, outro da reabilitação e outro da saúde. Eu me identifico com a ideologia da saúde que vem do paradigma da terapia ocupacional. E o núcleo central da intervenção em terapia ocupacional ainda é a relação triádica, a partir disso que nasce a intervenção. O Método da Terapia Ocupacional Dinâmica é a coisa mais importante que eu vou deixar de herança (Jô Benetton).

Acredito que existam perspectivas diferentes e que assim deva ser. O Método da Complexidade visa construir a unidade com a diversidade e a ausência de consenso, para a complexidade, não ameaça a unidade. A relação entre unidade e diversidade é o que constitui um sistema sustentável: tem que ter uma unidade e, ao mesmo tempo, tem que respeitar a diversidade. $O$ resultado disso é uma interação dinâmica, contextual e sistêmica. É isso que sustenta. Se acabar com a diversidade acaba a sustentabilidade do sistema e se não tiver unidade também não tem um sistema. Então, existem diferentes perspectivas e isso não é uma escolha, é uma condição da natureza, da história e assim deve ser (Lourdes Feriotti).

Eu acho que temos desenvolvido uma perspectiva Crítica na Terapia Ocupacional utilizando vários autores e várias correntes distintas. Poderíamos dizer que temos desenvolvido várias perspectivas criticas. [...] A perspectiva crítica vai problematizando as demais abordagens e perspectivas. Eu acho que estamos nesse momento de tentar, de pensar essa perspectiva critica de uma forma mais consistente [...]. Existe um movimento sempre de reduzir os problemas e a gente tem é que complexificar os problemas. [...] Eu sinto que não é suficiente a Teoria da Complexidade para pensar a Terapia Ocupacional Crítica, [...] é uma boa parceira, mas temos que buscar outros elementos e talvez formular melhor o que é isso. Essa tem sido minha preocupação do momento (Sandra Galheigo).

Denomino o meu estudo de epistemologia da terapia ocupacional, no sentido da busca por fazer uma arqueologia do conhecimento da terapia ocupacional, conceitualmente. [...] Eu tenho uma concepção de terapia ocupacional como Produção de Vida e de atividade como criação de território existencial, mas não é um método e nem somente uma forma de compreender, é uma forma de fazer pensar a terapia ocupacional. [...] 
Essa coisa que a gente chama de atividade e que territorializa a existência; a existência se dá na atividade. A ideia da atividade como território existencial foi ficando cada vez mais forte para mim, porque é onde a vida acontece (Mariangela Quarentei).

Existe uma terapia ocupacional social e isso significa que existem outras terapias ocupacionais, de outro jeito [...]. Eu acho que toda a terapia ocupacional quer produzir inserção social - entendida como uma vida mais autônoma, com participaçáo, liberdade. O como ela vai chegar nisso é diferente [...]. A perspectiva social da terapia ocupacional está no campo social sem dúvidas, ela olha para outras problemáticas, para outras metodologias, para outros focos. Eu acho que a minha perspectiva da terapia ocupacional em geral tem a ver a com a realização da vida com autonomia, participação [...]. Neste momento, a minha perspectiva é de que a terapia ocupacional necessariamente lida, ao produzir a sua função, com a questão social. Para olhar a especificidade na terapia ocupacional eu tenho a perspectiva social, olhando para as diferenças (Roseli Lopes).

Salienta-se que todo conhecimento elaborado pelas interlocutoras, com seus respectivos grupos de trabalho, pesquisa ou parcerias pessoais, podem ser acessados em uma série de produçôes, relatórios, pesquisas, publicaçôes, palestras, apresentações em eventos, entre outros. Os trechos anteriores apresentam suas vozes em um retrato histórico, enquanto protagonistas contemporâneas desta construção do campo, assim como compreensóes na afirmação de conhecimentos em/sobre terapia ocupacional no Brasil.

\section{Forças e resistências em evidência}

Diante das expressões singulares, faz-se necessário remeter créditos às redes amplas, que instigam e oferecem suporte para investimento na produçáo de conhecimento da terapia ocupacional. Desde o momento de se tornar terapeuta ocupacional até a sua efetivação técnica e contribuição teórica, há influências e suportes importantes oferecidos por colegas que estão passando ou já passaram por esses processos. O encontro entre Sandra Galheigo, Roseli Lopes e Denise Barros, por exemplo, foi convocado por estarem vivendo concomitantemente a extinção de disciplinas de terapia ocupacional social nos cursos em que eram docentes, o que mobilizou a criação de um coletivo (Metuia), para estimular a reflexão e a produção da terapia ocupacional junto às questôes sociais.

O trabalho voltado para a produção acadêmica na terapia ocupacional brasileira também esteve relacionado à crítica elou resistência aos padrôes acadêmico-científicos. São relatados os embates da formação, construção e divulgação do conhecimento, os temas priorizados e aqueles invisibilizados pela ciência hegemônica, entre outros, além de suas influências sobre o reconhecimento científico da profissão, o investimento e os recursos para produçáo e pesquisa, o desenvolvimento da pós-graduação e toda a cadeia de conhecimento e reconhecimento atrelada a esse campo. Parece inevitável o dilema sobre a submissão à lógica produtivista versus as possibilidades do pensar-produzir criativo, sensível e autônomo.

Estar fora ou à margem dessa dinâmica acadêmica possibilita certo grau de liberdade, mas também permanecem as dificuldades para dialogar sobre produção de conhecimento e sobre o reconhecimento destes saberes produzidos fora das instituiçóes consagradas. Entram em debate as questóes sobre significado, método e legitimidade científica. 
Algumas interlocutoras relatam sobre a cisão entre teoria e prática, entre os profissionais que trabalham na assistência e os da docência/pesquisa, subentendendo a produção de conhecimento como função estritamente acadêmica. Essa é uma lógica, segundo Galheigo (2014), que valoriza mais a criação de classificaçóes hierárquicas entre os agentes envolvidos do que a construção de práticas e saberes.

Na resistência, Jô Benetton, Maria de Lourdes Feriotti e Mariangela Quarentei, por exemplo, criaram grupos de estudos e desenvolveram métodos, concepçóes e produçóes independentes desse paradigma - ainda que tenham procurado, em algum momento, configuraçóes possíveis de contribuiçáo na institucionalizaçáo acadêmica, seja pela docência na graduação, pela orientação de estágios curriculares ou pela coordenação de aprimoramento profissional.

Lourdes e Mariangela, inclusive, aproximaram-se de perspectivas no sentido da complexidade e da expansão dos saberes, distanciando-se da rigidez acadêmica e afirmando suas produçôes com rigor, criatividade, liberdade e prazer, podendo usufruir também de outras lógicas de tempo, produção, aprendizagens e certificação.

Eu estou trabalhando o tempo todo contra a instituição de um modelo homogêneo ou hegemônico de uma terapia ocupacional. (Lourdes Feriotti).

Nunca tentei fazer uma teoria e metodologia fechada, isso é muito meu, pois sou uma pessoa capaz de lidar com situaçóes bastante descontínuas e fragmentadas. (Mariangela Quarentei).

Fica ressaltado em suas narrativas o encantamento por conhecer e, posteriormente, fazer e criar essa profissáo que marcou suas relaçóes com a terapia ocupacional. O desafio pelo desconhecido e a dificuldade de exercer a profissão impulsionaram suas produçóes.

A terapia ocupacional, antes de mais nada, é uma profissão que se colocou o desafio, diante das dificuldades dos individuos e grupos, às vezes, dificuldades bastante sérias, de fazer a vida poder acontecer de uma forma melhor. A profissão [...] nasceu dentro de espaços como o hospital, mas olhando para a vida lá fora. Não tenho dúvidas que ela quer produzir vida, a vida ou as vidas, para pessoas que estáo com muita dificuldade. [...] É uma profissão e um profissional que, diante de muitas dificuldades da vida acontecer, quer trabalhar com a possibilidade de que ela aconteça melhor. (Roseli Lopes).

O que eu acho que é bonito na terapia ocupacional é que enfrentamos, com as pessoas, muitos agravos em relação à potência de atividades delas no mundo, e desenvolvemos conhecimento sobre a potência da atividade. Penso que vida é a potência de atividade no mundo. (Mariangela Quarentei).

Apesar das dificuldades que se apresentam, todas as interlocutoras referiram sentir prazer em produzir conhecimento em/de/sobre terapia ocupacional. Contam de suas trajetórias com grande afeto, paixão e satisfação pela profissão, seus desafios e possibilidades, pelo que construíram nela. Elas fazem parte de geraçôes com poucos terapeutas ocupacionais no país, assim, as memórias afetivas das relaçóes construídas, de quem eram seus colegas e as trocas evidenciam um círculo de nomes hoje reconhecidos que auxiliaram ativamente a construção da profissão.

A dificuldade de exercer a profissão que me fez produzir. A terapia ocupacional é o núcleo central na minha vida (Jô Benetton). 
O mestrado foi dando uma sensação de que estávamos inventando uma terapia ocupacional que era nossa. É o significado que tem na minha vida: acreditar que é muito importante a gente trabalhar e construir a profissäo (Sandra Galheigo).

Um dos significados da terapia ocupacional na minha vida é que, talvez, ela tenha me autorizado a validar e valorizar, de fato, a criatividade, a liberdade e a necessidade de fazer um trabalho com significado e prazer (Lourdes Feriotti).

A terapia ocupacional é um importante campo para o exercício sagrado do cuidar da vida, da existência... e para o exercício do compartilhamento da existência e do conhecimento sobre esse cuidar (Mariangela Quarentei).

A terapia ocupacional é constitutiva, nessa trajetória que segui, com essas pessoas que estiveram comigo, isso que também é uma rede de suporte para a vida (Roseli Lopes).

Diante de tais reflexões singulares-plurais, vê-se situações, escolhas e características que mantêm a constante formação, reformulação ou transformação do conhecimento em uma composição criativa, inventiva e diversa. Há muitas potências emergidas nessas histórias e produçóes, mas fica evidente o protagonismo dessas cinco mulheres interlocutoras e suas atuaçóes diante da falta e do questionamento, enfrentando dificuldades para construir o que hoje chamamos de terapia ocupacional no Brasil. Acima de tudo, construir conhecimento diretamente relacionado ao fazer terapia ocupacional, ao acreditar na potência dessa profissão, nos seus desafios e nos encantamentos.

\section{Consideraçóes em constante construção}

O trabalho evidenciou o protagonismo de cinco interlocutoras, reconhecendo que a história é composta de trajetórias singulares e coletivas, consequentemente interconecta ainda um grupo plural de profissionais que nem sempre é evidenciado. A história é sempre compartilhada, coletiva, coexistindo inúmeras versôes dos fatos, e também são múltiplas redes que tecem e sustentam diferentes produçôes. Não se ignora, entretanto, a existência de divergências e controvérsias, já que, ao considerar "versôes" sobre a história e "reconhecimento", inclusive acadêmico e/ou científico, inevitavelmente estamos considerando interpretaçóes, valores, marcadores sociais e simbólicos, hierarquias e disputas internas e entre campos (Bourdieu, 1989, 2004).

É evidente que a terapia ocupacional, ao desenvolver seu campo de conhecimento, como qualquer outro, estabelece-se como um campo de forças, lutas e disputas (Bourdieu, 2004), mesmo que este texto não tenha explorado tal questão, pois optou-se por caminhar na contramão e exercitar um diálogo profissional mais afetuoso, não hierarquizado e de reconhecimento de esforços individuais e coletivos pela profissão. Nesse sentido, valorizase o fortalecimento de sua identidade, possibilidade do comum pela via da solidariedade entre as singularidades que compóem sua pluralidade.

A implicação da pesquisadora nesse campo de forças, cuja formação tem se dado no contexto apresentado (estado de São Paulo), também incorpora contradições e hierarquias que se exercem. Afirmou-se, entretanto, uma perspectiva sensível no sentido da composiçáo diversa, ou seja, da criação entre terapias ocupacionais produzidas. Guiou-se pela curiosidade sobre as narrativas, em um processo afetivo que acompanhou encantamentos constitutivos e construtivos das trajetórias. O impacto desse modo de pesquisar incidiu sobre a conclusão da 
pesquisa, o que requereu acolhimento de seu inacabamento e do tempo alargado que se fez necessário para compreensão de alguns resultados.

Olhando para os processos dessas trajetórias, a escassez de recursos, os embates macroestruturais externos ao campo comum e a superação de desafios priorizando a criação com novos sentidos, engajamento e encantamento, deparamo-nos com características comumente atribuídas ao profissional terapeuta ocupacional na atualidade. Acompanhar processos singulares convocou a olhar para percursos compartilhados, para a busca insaciável por responder demandas complexas e, conjuntamente, tecer fios dessa rede compartilhada que vem conduzindo um perfil e uma identidade profissional.

Em 2004, Roseli apontou a reflexão entre um caminho geral e processos singulares na terapia ocupacional no estado de São Paulo, tanto em relação à construção da atuação técnica quanto à sistematização e divulgação do conhecimento por meio de publicaçóes. Ela destacou a diversidade das terapias ocupacionais que estavam se desenhando e o intuito comum de investir nesse campo de produção de saberes complexos. O que ela chamou de singular e geral também se trata da articulação entre a expansão de um campo interdisciplinar, intersetorial e interprofissional, sem perder de vista as especificidades do núcleo profissional (Lopes, 2004).

Neste trabalho, foram destacadas 14 categorias temáticas dessa cartografia que evidenciou o singular, o plural e o comum, indicando tessituras e sustentação de uma rede de conhecimentos da terapia ocupacional no Brasil, com características heterogêneas e compartilhadas de um perfil profissional com:

a) interesse pelo desconhecido; b) graduação incipiente e precária; c) formação continuada em terapia ocupacional; d) marcas da repressão e resistência do/ao Regime Militar; e) desenvolvimento e organização política da categoria; f) investimentos à pesquisa em terapia ocupacional; g) compreensôes sobre especificidades da profissão; h) adoção e/ou enunciação de concepções, perspectivas, métodos ou campos; i) redes amplas, que instigam e oferecem suporte para investimento na produção de conhecimento; j) crítica e/ou resistência aos padróes acadêmico-científicos; k) o encantamento por conhecer e, posteriormente, fazer e criar essa profissão; l) prazer em produzir conhecimento em/de/sobre terapia ocupacional; $\mathrm{m}$ ) protagonismo feminino; $\mathrm{n}$ ) construção de conhecimento diretamente relacionado ao fazer terapia ocupacional.

Tais aspectos exerceram um papel instigador e decisivo no desenvolvimento das trajetórias individuais e coletivas na profissão rumo à construção de seu campo de conhecimentos. Tais dados ajudaram a sistematizar histórias da profissão no país, refletem sobre o desenvolvimento da sua identidade, indicam caminhos e expressam características que contribuem ao conhecimento específico da terapia ocupacional no Brasil.

Como um compromisso ético, este trabalho também esgarça o instituído pela ciência hegemônica, no que diz respeito às formas, aos objetos e aos interlocutores, no sentido de reconhecer, romper e encontrar outros caminhos para construir conhecimento sem perpetuar a hierarquia dos saberes, as desclassificaçóes e/ou subjugamentos entre temáticas, grupos, áreas ou campos. Neste sentido, vê-se que a terapia ocupacional investe no que Bourdieu (1998) chamou de objetos ignóbeis, ou seja, aqueles menos investidos dentro do campo científico, contudo, não menos importantes do ponto de vista social, para a promoção, produção e qualificação das vidas das pessoas e coletivos.

Assim, opera-se na manutenção do debate específico e transversal da terapia ocupacional brasileira, contemplando sua pluralidade teórico-prática a partir de inserçôes singulares no 
campo da produção de conhecimento, reconhecendo suas potencialidades e limites. Por fim, indica-se caminhos para o desenvolvimento criativo de novas possibilidades, para o fortalecimento do (re)conhecimento da terapia ocupacional brasileira comprometida e engajada com a diversidade das demandas de seu contexto e cultura, cada vez mais urgentes e complexas.

\section{Referências}

Adichie, C. N. (2009). The danger of a single story, TED Talks. TED. Recuperado em 21 de maio de 2018, de www.ted.com/talks/chimamanda_adichie_the_danger_of_a_single_story

Barros, D. D., Ghirardi, M. I. G., \& Lopes, R. E. (2002). Terapia ocupacional social. Revista de Terapia Ocupacional da Universidade de São Paulo, 13(3), 95-103.

Bosi, E. (1994). Memória e Sociedade: lembranças dos velhos. São Paulo: Companhia das Letras.

Bourdieu, P. (1989). O poder simbólico. Rio de Janeiro: Bertrand Brasil

Bourdieu, P. (1998). Método científico e hierarquia social dos objetos. In M. Nogueira \& A. Catani (Eds.), Escritos de Educação (pp. 33-38). Rio de Janeiro: Vozes.

Bourdieu, P. (2004). Os usos sociais da ciência: por uma sociologia clínica do campo cientifico. São Paulo: UNESP.

Cardinalli, I. (2017). Conhecimentos da terapia ocupacional no Brasil: um estudo sobre trajetórias e produçôes (Dissertação de mestrado). Universidade Federal de São Carlos, São Carlos. Recuperado em 11 de setembro de 2018, de https://repositorio.ufscar.br/handle/ufscar/8496

Emmel, M. L. G., \& Lancman, S. (1998). Quem são nossos mestres e doutores? o avanço da capacitação docente em terapia ocupacional no Brasil. Cadernos de Terapia Ocupacional da UFSCar, 7(1), 29-38. Recuperado em 7 de maio de 2015, de http://www.cadernosdeterapiaocupacional.ufscar.br/index.php/cadernos/article/view/264/216

Francisco, B. R. (2001). Terapia ocupacional. Campinas: Papirus.

Furtado, E. A. (1999). Conversando sobre identidade profissional. Revista de Terapia Ocupacional da Universidade de São Paulo, 10(2-3), 46-48.

Galheigo, S. M. (1999). Transdisciplinaridade enquanto princípio e realidade das açōes de saúde. Revista de Terapia Ocupacional da Universidade de São Paulo, 10(2-3), 49-54.

Galheigo, S. M. (2007). As discussões "fundamentais" da terapia ocupacional: retrospectiva histórica, percursos e perspectivas. In Anais do $10^{\circ}$ Congresso Brasileiro de Terapia Ocupacional. Goiânia.

Galheigo, S. M. (2014). Sobre identidades, latinoamericanidades e construção de saberes em terapia ocupacional. Cadernos de Terapia Ocupacional da UFSCar, 22(1), 215-221.

http://dx.doi.org/10.4322/cto.2014.023.

Lancman, S. A. (1998). Influência da capacitação dos terapeutas ocupacionais no processo de constituição da profissão no Brasil. Cadernos de Terapia Ocupacional da UFSCar, 7(2), 49-53. Recuperado em 12 de maio de 2016, de http://www.cadernosdeterapiaocupacional.ufscar.br/index.php/cadernos/article/view/253/205

Lancman, S., \& Emmel, M. L. G. (2003). La recherche en ergothérapie: développement de la formation des enseignants au Brésil. Canadian Journal of Occupational Therapy, 70(2), 97-100.

Lima, E. M. F. A. (1997). Terapia ocupacional: um território de fronteira. Revista de Terapia Ocupacional da Universidade de São Paulo, 8(2/3), 98-101.

Lima, E. M. F. A. (1999). Identidade e complexidade: composiçôes no campo da terapia ocupacional. Revista de Terapia Ocupacional da Universidade de São Paulo, 10(2-3), $42-45$.

Lopes, R. E. (1991). A formação do terapeuta ocupacional: o curriculo: histórico e propostas alternativas (Dissertação de mestrado). Universidade Federal de São Carlos, São Carlos.

Lopes, R. E. (2004). Terapia ocupacional em São Paulo: um percurso singular e geral. Cadernos de Terapia Ocupacional da UFSCar, 12(2), 75-88. Recuperado em 12 de maio de 2015, de http://www.cadernosdeterapiaocupacional.ufscar.br/index.php/cadernos/article/view/181/138 
Machado, M. C. (1991). Rumo à ciência da atividade humana. Revista de Terapia Ocupacional da Universidade de São Paulo, 2(2/3), 60-65.

Mângia, E. F. (1998). Apontamentos sobre o campo da terapia ocupacional. Revista de Terapia Ocupacional da Universidade de Sáo Paulo, 9(1), 5-13.

Mângia, E. F. (1999). Terapia ocupacional: práticas, discursos e a questão da legitimidade científica. Revista de Terapia Ocupacional da Universidade de São Paulo, 10(2-3), 55-59.

Medeiros, M. H. R.(2010). Terapia ocupacional: um enfoque epistemológico e social. São Carlos: EdUFSCar.

Nascimento, B. A. (1990). O mito da atividade terapêutica. Revista de Terapia Ocupacional da Universidade de São Paulo, 1(1), 17-21.

Nora, P. (2016). Entre memória e história: a problemática dos lugares. Projeto História, (10), 7-28. Recuperado em 10 de setembro de 2016, de http://revistas.pucsp.br/index.php/revph/article/viewFile/12101/8763

Oliver, F. C. (2008). Pesquisa e produção bibliográfica em terapia ocupacional: contribuiçóes ao debate sobre parâmetros de avaliação da produção acadêmica brasileira. Revista de Terapia Ocupacional da Universidade de São Paulo, 19(2), 108-120. http://dx.doi.org/10.11606/issn.2238-6149.v19i2p108-120.

Passos, E., Kastrup, V., \& Escóssia, L. (2012). Pistas do método da cartografia: pesquisa-intervenção e produção de subjetividade. Porto Alegre: Sulina.

Pinto, J. M. (1990). As correntes metodológicas em terapia ocupacional no Estado de São Paulo (1970-1985) (Dissertação de mestrado). Universidade Federal de São Carlos, São Carlos.

Pollak, M. (1992). Memória e identidade social. Estudos Históricos, 5(10), 200-212. Recuperado em 12 de setembro de 2016, de http://bibliotecadigital.fgv.br/ojs/index.php/reh/article/view/1941/1080

Quarentei, M. S. (1999). Marcas na construção do conhecimento. In Anais do $6^{\circ}$ Congresso Brasileiro de Terapia Ocupacional. Águas de Lindóia.

Salles, M. M., \& Matsukura, T. S. (2016). Conceitos de ocupação e atividade: os caminhos percorridos pela literatura nacional e de língua inglesa. In M. M. Salles \& T. S. Matsukura (Eds.), Cotidiano, atividade humana e ocupaçâo: perspectivas da terapia ocupacional no campo da saúde mental (pp. 13-35). São Carlos: EdUFSCar.

Schmidt, M. L. S., \& Toniette, M. A. (2008). A relação pesquisador-pesquisado: algumas reflexôes sobre a ética na pesquisa e a pesquisa ética. In I. C. Z. Guerriero, M. L. S. Schmidt \& F. Zicker (Eds.), Ética nas pesquisas em ciências humanas e sociais na saúde (pp. 102-106). São Paulo: Aderaldo \& Rothschild.

Soares, L. B. T. (1991). Terapia ocupacional: lógica do capital ou do trabalho? São Paulo: Hucitec.

\section{Contribuiçáo dos Autores}

Isadora Cardinalli e Carla Regina Silva foram responsáveis pela concepção, redação e revisáo do texto, organização de fontes e análises. Carla Regina Silva foi orientadora da pesquisa. Todos os autores aprovaram a versão final do texto.

\section{Fonte de Financiamento}

Coordenação de Aperfeiçoamento de Pessoal de Nível

Superior - CAPES. Código 001.

\section{Autor para correspondência}

Isadora Cardinalli

e-mail: isadora.cardinalli@gmail.com.

\section{Editora de seçáo}

Profa. Dra. Sandra Maria Galheigo 